\title{
Factors Influencing Domestication or Foreignization on the Macro and Micro Levels
}

\author{
Wenfen Yang \\ Qingdao University of Science \&Technology, China \\ Email: wfyoung@163.com
}

\begin{abstract}
This essay gives a brief study of factors influencing Domestication and Foreignization he macro and micro levels. Domestication designates the type of translation in which a transparent, fluent style is adopted to minimize the strangeness of the foreign text for target language readers; while foreinignization means a target text is produced which deliberately breaks target conventions by retaining something of the foreignness of the original. As translation is something of a negotiation between the source text author, target text reader and translator, it indicates that translating activities are subject to the influence of outside factors, so domestication and foreignization are no exception. Those factors can be classified into two levels: macro-factors and micro-factors. Translation strategies selected by a translator determine the whole orientation of his translation; they permeate every step in the whole process of translating as well. Domestication and foreignization are subject to the influence of many factors, which can be classified into two levels: macro-factors and micro-factors.
\end{abstract}

Index Terms - domestication, foreignization, macro and micro factors

Domestication and Foreignization are two basic translation strategies which provide both linguistic and cultural guidance. Generally speaking, domestication designates the type of translation in which a transparent, fluent style is adopted to minimize the strangeness of the foreign text for target language readers, while foreignization means a target text is produced which deliberately breaks target conventions by retaining something of the foreignness of the original (Shuttleworth \& Cowie, 1997, p. 59). Translation strategies selected by a translator determine the whole orientation of his translation; they permeate every step in the whole process of translating as well. Domestication and foreignization are subject to the influence of many factors, which can be classified into two levels: macro-factors and micro-factors.

In order to find out the factors influencing translation strategies first of all it inevitably entails the overview of the process of translation. It is usually as follows:
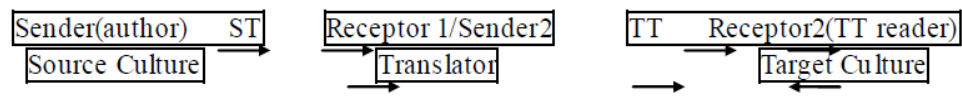

The ST author is the message sender, and translator is the receptor of the ST message as well as the sender of the message to the TT reader. The author and the ST belong to the SC, while the TT and the TT reader belong to the TC. Therefore, the factors involved in the process of translation include: the author, the source text, the translator, the target text, the TT reader, the SC and the TC.

From the pattern presented above, it is obvious that translation is something of a negotiation between the source text author, target text reader and translator. Moreover, "translation does not happen in a vacuum, but in a continuum; it is not an isolated act, it is part of an ongoing process of intercultural transfer. Moreover, translation is a highly manipulative activity that involves all kinds of stages in that process of transfer across linguistic and cultural boundary." (Bassnett \& Trivedi, 1999, p. 2) It indicates that translating activities are subject to the influence of outside factors, so domestication and foreignization are no exception. Those factors can be classified into two levels: macro-factors and micro-factors.

\section{MACRO-FACTORS}

Macro-factors project translators to historical and social screen. They include cultural asymmetry, historical background, language reality, political interference, ideology, aesthetic stereotype and needs of the TT reader.

\section{A. Cultural Asymmetry}

Culture asymmetry refers to the disparity existing between cultures. Due to cultural disparity, communication between cultures of lower prestige and cultures of higher prestige are not equal. According to the polysystem hypothesis proposed by Even-Zohar (Gentzler, 1993, p. 119), when translated literature assumes a primary position, the borders between translated texts and original texts 'diffuse' and definitions of translation become liberalized. Governed by a situation where their function is new work into the receiving culture and change existing relations, translated texts necessarily tend to more closely reproduce the original text's forms and textual relations, ... thus the codes of both the receiving culture's original literature and the translated literature become 'enriched'. In other words, when a nation's 
literature and culture are dependent on the translation, translators tend to adopt foreignization to show the exotic style as much as possible. The opposite social conditions, as Even-Zohar suggests, govern the situations in which translation is of secondary importance to the polysystem. In this historical situation, translation often (but not always) assumes the already established as a dominant type within a particular genre, and the translation tends to remain fairly conservative. The translators' attempt to find ready-made models for translation results in translations that conform to preestablished aesthetic norms in the target culture at the expense of the text's 'original form' (Gentzler, 1993, p. 119). That is to say, when translation is at a marginal position of the whole polysystem, translators tend to employ domestication to cater for the norms and tastes of the receiving culture.

The cultures of those nations that are more economically and politically advanced are usually regarded as superior to the cultures of those nations that are less developed, and so in the developed nations, the translated literature usually occupies a periphery position, while in the developing countries, the translated literature occupies a central position. Thus when the literary works of high-status culture are translated into low-status culture, the foreign flavour is likely to be preserved as much as possible, and when the literary works of low-status culture are translated into high-status culture, source texts are likely to be adapted to adhere to the norms of the target culture.

As the Great Britain and the USA are politically and economically more advanced than other countries, translations in English-speaking countries have been dominated by "fluent translation" (Venuti, 1995, p. 43), or domesticating translation. The most welcomed translations are those in which the domesticating strategy is adopted. The standard adopted by critics to judge if a translation is successful is that it should sound like a piece of native work. Besides, the books translated into other languages far outnumbered the books that are translated into English. According to a statistics done by L. Venuti (Venuti, 1995, p. 13-14), British and American book production increased fourfold since the 1950s, but the number of translations remained roughly between 2 and 4 percent of the total. Western European publishing also burgeoned over the past several decades, but translations have always amounted to a significant percentage of total book publication, and this percentage has consistently been dominated by translations from English.

Take Egypt as the contrary instance, it once lost its cultural independence, because it had lost its political independence. Unconditional exposure to strong culture led to the change in the choice for translation strategies. Before Egypt fell into a colony, literary translation focused on domestication. After that, with the appearance of the split cultural personality, literary translation shifted to foreignization which "imposed the western classics on Egyptian culture and swallowed western value system without questioning the correctness of doing so.” (Han Ziman, 2000, p.42)

The two examples cited above reveal the involvement of strong culture and weak culture in deciding desired translation strategy.

\section{B. Historical Background}

Toury(1998) argues that translation "as an act and as an event is characterized by variability, it is historically, socially and culturally determined." Most literary works bear a marked brand of the times in which they are written. Human beings exist historically and are constrained by particularities and limitations of history. In the course of history, exchanges between different countries and different peoples are a dynamic process instead of a stagnant one. So is the case of translation. For example, during the late Qing period when China was threatened by foreign invasions and in danger of national subjugation and genocide, political interpretation of foreign fiction with little or no political color prevailed in the literary translation, for the patriotic scholars attempted to educate the mass by means of translating foreign fictions. To reinforce the educational function, they even inserted their own political viewpoints in the translated texts (Wang Hongzhi, 2000, p. 2). Nowadays, with technology progressing in an ever-increasing rate, the whole earth has turned into a global village. Diverse channels are opened to facilitate communication. The heterogeneity in one culture is more easily tolerated by other cultures. For example, Chinese expressions such as "iron bowl" (Tie Fan Wan), "Gongfu"(Gong Fu), Taiji Quan" (Tai Ji Quan), are also present in English. The example indicates the rise of foreignization in modern time.

\section{Language Reality}

Although Nida made his effort to create an unbiased atmosphere in dealing with different languages and cultures, which enhances the verbal communication and understanding of the entire human beings. His attitude toward different languages and cultures is manifest in the "each language has its own genius." (Nida \& Taber, 1969, p. 3) Nida admits that besides the common ground shared by languages, each of them possesses its own features. For example, those peculiar linguistic phenomena in different languages, as "plays on words, rhythm of poetry, the acrostic features of many poems, and the frequent intentional alliteration" (ibid.: p.4), can hardly be fully reproduced. He affirms that "anything that can be said in one language can be said in another, unless the form is an essential element of the message." (ibid.: p.4)

The nature of the ST is another element that should be taken into account. Translation between two languages from different families is more difficult than that between those from the same family. Moreover, when the source culture is geographically or temporally distant from or otherwise alien to the target culture, translation should be coded with more caution. Just as Lefevere (1992a, p. 70) puts it: "If a text is considered to embody the core values of a culture, if it functions as that culture's central text, translations of it will be scrutinized with the greatest of care, since 'unacceptable' translations may well be seen to subvert the very basis of the culture itself." Bassnett also suggests the translators 
consider the nature of the text. If the sourse text is meta-narrative or a central text that consists of a nation's core beliefs, Bassnett proposes translating in a literal way, i.e. adopting foreignization method (Liao Qiyi, 2001, p. 365).

\section{Political Interference}

Political interference refers to the fact that politics in a specific society often exerts influence upon translation strategy. Generally speaking, the more politically sensitive the translator is, the more obvious the marks of his political likes and dislikes are. The political consciousness is more or less detectable when put into different political backgrounds. Ample examples can be found in this regard. Colonial governments strengthened their hegemony through translations that were inscribed with the colonizer's image of the colonized, an ethnic or racial stereotype that rationalized domination. William Jones, the eighteenth-century scholar and judge in the service of the East India Company, translated Sanskrit legal texts because he suspected the reliability of Indian interpreters and sought to restore Indian law to its ancient purity which it turned out, supported the Company's commercial ventures. Besides, whether the ruling class supports and whether its policy is lenient in the target culture are also important factors influencing translation strategy. Translation practice in China is open to political interference. During the 1950s, class struggle was imposed as the primary norm for categorizing literary works during this period. Generally speaking, only literary works from the Soviet Union and other socialist countries, as well as former colonies of European countries, were deemed to be qualified for translation. Thus, there was strict control of textual selection during this period, a control exercised in accordance with the predominant political orientation. As for Western literary works, particularly American and English literature, only those depicting class struggle and racial discrimination - that is, only those exposing the dark side of capitalist society — were deemed worthy of translation. Consequently, Uncle Tom's Cabin was selected for its delineation of racial oppression and Oliver Twist for its portrayal of capitalist exploitation. Many other masterpieces, James Joyce's Ulysses for one, were labelled as decadent and reactionary; they remained untranslated until the early 1990s.

\section{E. Ideology}

Ideology is the link between what we say, what we believe in and the social conventions or establishments. Ideology, to its core, is a descriptive form towards thinking in reality. People's reaction to certain economic-social environment may change into ideology. Broadly speaking, when such reaction gets involved in social conflicts and fulfils specific social function, it is viewed as ideology. Translation, as a kind of social practice, is no exception. On the one hand, translation is governed by ideology. On the other hand, translation at the same time contributes to production of ideology. The ideology dictates the basic strategy the translator is going to use and also dictates the selection of the content of the original. Toury found that most texts were chosen to translate for ideological reasons (Gentzler, 1993, p.126). Andre Lefevere(Lefevere, 1992b) claimed ideology as determining factors in the process of translation. He holds that in every level of the translation process, if linguistic considerations enter into conflict with considerations of an ideological and/or poetiological nature, the latter consideration tends to win (Lefevere, 1992a, p.24). Chinese and the Westerners hold different ideology. Chinese lay stress on the three cardinal guides (i.e. ruler guides subject, father guides son, and husband guides wife) and the constant virtues (i.e. benevolence, righteousness, propriety, wisdom and fidelity, as specified in the feudal ethical code) while the Westerners attach importance to equality. Chinese uphold favouritism while the Westerners advocate merit. Chinese are ruled by the doctrine of being filial while the Westerners are governed by the principle of being impartial. Honglou Meng is a superb integrity of social values and deep-rooted the family-centered Confucian ethics, but to most western readers lacking of profound knowledge of the ancient Chinese ideology, the version of the Story of the Stone by David Hawks is no more than a melancholy love story. Lu Xun once said that from Honglou Meng, different readers may approach the same text from various perspectives. A person engaged in Jing reads Yi; a person of Taoist school reads obscenity; a scholar reads sentiment; a revolutionist reads rebellion against Man nationality, a gossip reads secrets of the royal court ... The effect of the same text varies so greatly with the readers of different ideologies in the same culture, let alone the readers of a different culture. All in all, the ideology of a specific society displays exclusiveness to certain extent. The process of translating requires the translator to take into account the conflict between different ideologies.

\section{F. Aesthetic Stereotype}

Aesthetic stereotype of a people is associated with the pattern of thinking. Ideas of what is beautiful differ greatly from one culture to another. Chinese people, under the influence of its ideographic language, are good at thinking in images while people in the west, under the influence of their phonographic language, are more apt at thinking in logic. Two different thinking patterns naturally result in two different aesthetic stereotypes. Chinese people judge what is beautiful from the angle of image while people in the west consider what is beautiful from the angle of logic. The ideography of Chinese language also brings about people's preference for symmetric structure. Another distinctive difference between the two aesthetic stereotypes lies in the different literary regularities put forward by two different cultures. Such difference not only leads to different writing styles but also forms different aesthetic values.

From a diachronic point of view, the aesthetic stereotype of a specific people demonstrates resistance when facing a strange aesthetic stereotype at an initial stage and domesticating strategy seems to be the solution. Heylen studied the six French versions of Hamlet and found some interesting points. In the version published in 1770, the translator Ducis 
omitted such parts as the duel between Hamlet and Laertes, Gertrude's drinking up the poisoned wine, only for the sake of adjusting to traditional French aesthetic stereotypes. In the version published in 1846, the translators Alexandre Dumas and Paul Meurice let Hamlet survive simply because aesthetic stereotypes dwelt at the nation that hero can not die (Heylen, 1993, p.49).

Aesthetic stereotype, though time-hardened, is not rigid. With more and better understanding achieved, the resistance of aesthetic stereotype becomes weakened accordingly and foreignization is recognized as an adoptable translation strategy. Take Ezra Pound as an instance, who keeps the aesthetic uniqueness of ST as well as the linguistic norms and endues great success. He keeps the syntactic structures and images of the source texts in his translation of Chinese poems. A typical example is that he translates Li Bai's line "Huang Cheng Kong Da Mo" into "Desolate castle, the sky, the wide desert." This translation almost violates the English syntactic norm. There is no preposition, subject or predicate in the translation, however, the syntactic structure and the rich images of the ST are kept. It faithfully renders the style of the original poem and presented before the western readers the way that the ancient Chinese poets write poems. This kind of translation certainly astonished the western readers, but they were warmly welcomed by the American readers and were very influential in American literature history. It was exactly under the influence of ancient Chinese poems that the American imagist poems flourished.

\section{G. Needs of the TT Reader}

The translation process involves not only the translator's but also the readers' work. A translation process is not complete without the participation of the readers. It seems to the theorists that the addressee, who is the intended receiver or the audience of the target text with their culture-specific world-knowledge, their expectations and the communicative needs, plays crucial part in translation. Nida (1995, p. 139) once said: "The target audience for which a translation is made almost always constitutes a major factor in determining the translation procedures and the level of language to be employed." Charles S. Draszewski (1998, p. 4) also argues that "the needs of the specific audience which the translator wants to reach via his/her work should be the overriding, determining factor in deciding just how he or she is to approach the specific translation project." In this aspect, both domestication and foreignization are justified. Lefevere attaches great importance to the type of target readers. He believes that the type of target readers determines translation strategies. "Translation then, is not just a process that happens in the translator's head. Readers decide to accept or to reject translations. ... If you want to influence the masses, a simple translation is always best. Critical translations vying with the original really are of use only for conversations the learned conduct among themselves." (Lefevere, 1992, p. 6) Newmark also believes that the type of target readers is an important factor in affecting the choice of translation strategies. "Summarizing the translation of cultural words and institutional terms, I suggest that here, more than in any other translation problems, the most appropriate solution depends not so much on the collocations or the linguistic or situational context (though these have their place) as on the readership (of whom the three types: expert, educated generalist, and uniformed, will usually require three different translations)." (Newmark, 1988, p.102)

\section{MICRO-FACTORS}

Micro-factors are more translators-oriented compared to macro-factors. Nida (Nida, 1964a, p. 145-154) once said: "Since the translation itself is the focal element in translating, ... his role is central to the basic principles and procedures of translating. ... No translator can avoid a certain degree of personal involvement in his work." Micro-factors include purpose of translation and translator's attitude toward ST and his cultural attitude.

\section{A. Purpose of Translation}

According to skopos theories, the position and function of what's considered to be a translation in a given culture are determined by the target culture and that translations are first and foremost 'facts of target cultures' (Toury, 2001, p. 29). Vermeer (Nord, 2001, p. 12) understands translation as "to produce a text in a target setting for a target purpose and target addressees in target circumstances." That is to say, translation strategies are in service of translation purpose. Hence, the translators are endowed with the right to employ whatever strategy that hands him the key to the specific problem he has at hand, provided that the purposes he intends to achieve are best realized in the responses of his readers. For example, during the late Qing and Ming period, Lin Shu's translation of the western fictions was disloyal to source text authors, however, no one can deny the significance of Lin Shu's translations, for in most prefaces to his translations, Lin Shu declared his translations are purpose-oriented.

Vermeer thinks that "one of the most important factors determining the purpose of translation is the addressee, who is the intended receiver or audience of the target with their culture-specific world knowledge, their expectations and their communicative needs."(Nord, 2001, p. 12) The translation of Hong Lou Meng (i.e. the Story of the Stone or A Dream of Red Mansion) offers a good proof. Yang Xianyi aimed at helping westerners know more about the gem of Chinese culture while David Hawks aimed at satisfying the needs of ordinary readers who only read for fun not for analysis, so Yang Xianyi turned to domestication while David Hawks foreignization.

\section{B. The Translator's Attitude toward ST and His Cultural Attitude}


The translator plays two roles in the translation process: the receptor of the ST messages and the sender of the TT messages. He is first of all a receptor and reader, and his attitude toward the ST plays an important role in determining his macro translation strategy. The first step of translation is comprehension. Different people comprehend the same literary work differently, and the same book that is regarded as of high value may be regarded as of low value by others. According to Lefevere (1992a, p. 91), different attitudes developed toward the original give rise to different translational strategies. Take two versions of Gone with the Wind translated by $\mathrm{Fu}$ Donghua and Li Yeguang respectively as an example. Fu Donghua adopted domesticating strategy in his translation and his version reads more like a triangle love affair which happened in modern China than a story which happened during the American War. From the preface to the translation we can see the reason. Fu states: "After seeing the film and reading the original, I found that it is by no means a popular novel with low taste, though it is much inferior to the works of the ancient famous writers." He holds that "translating this kind of books is different from translating classics, and if it is translated literally, the readers would probably feel bored." On the contrary, in the preface to his translation, Li Yeguang thinks much higher of the novel: "With the guileless artistic tact of the author, the seriousness of the theme, the clearness of orientation, this novel is not merely catering to the taste of ordinary townspeople." Thus the foreignizing strategy is adopted, in which the linguistic and cultural content of the ST are preserved to a great degree.

Moreover, as the manipulator of translation, the translator, who always works in a specific cultural context, is a cultural and historical figure. It is a universal truth that "translators do not work in ideal and abstract situations nor desire to be innocent, but have vested literary and cultural interests of their own, and want [emphasis original] their work to be accepted within another culture. Thus they manipulate the source text to inform as well as conform with the existing cultural constraints." (Gentzler, 1993, p. 134) In fact, the objective position of a nation's culture is one thing and the subjective attitude toward that position is another thing. With regard to the translation strategies employed, translators' cultural attitude is more important. We can suppose that when the translators' subjective cultural attitude agrees with the objective position of target culture and source culture, their choice of translation strategy justifies the polysystem hypothesis (Wang Dongfeng, 2000, p.4). As far as the choice of translation strategies is concerned, translators' cultural attitudes are more important than the objective position of a culture. It is the translator himself who decides upon the desirable strategy and such decision-making conforms to translator's subjective judgment on which culture is superior (the target culture or the source culture) and which cultural value he would like to adjust to. As is observed by Lefevere (ibid: p.107), most people insist that their language belongs to the class of beautiful languages. This attitude may influence a translator's selection of strategy. When a translator thinks that his native language is superior to other languages, he is likely to adopt domesticating strategy when he translates literary works of other nationalities into his native language. In answering Xu Jun's letter on his translation of Le Rouge et Le Noir and defending his domesticating strategy, Luo Xinzhang argues that "had Le Rouge et Le Noir been written by Stahl in Chinese instead of in French, it would have been even more beautifully written." The reason is that "the Chinese language is more beautiful than the French language."(Luo, 1995, p.23). Obviously, his attitude influences his selection of strategy.

All in all, many a factor plays a part in deciding on the matter of domestication and foreignization. Domestication and foreignization go beyond the mere scope of translating itself. The final choice on either of them is a product of various macro-factors and micro-factors. Any attempt to discuss the matter, without regard to macroscopic perspective and microscopic perspective, runs the risk of making opinionated or not well-grounded judgment.

\section{REFERENCES}

[1] Shuttleworth, M. \& M. Cowie. (1997). Dictionary of Translation Studies. Manchester, UK: St Jerome Publishing.

[2] Bassnett, Susan \& Trivedi, H. (eds.). (1999). Post-colonial Translation: Theory and Practice. London: Routledge.

[3] Gentzler, Edwin. (1993). Contemporary Translation Theories. London \& New York: Routledge.

[4] Venuti, Lawrence. (1995). The Translator's Invisibility: A History of Translation. London \& New York: Routledge.

[5] Lefevere, Andre. (1992a). Translation, History, Culture: A Sourcebook. London \& New York: Routledge.

[6] Lefevere, Andre. (1992b). Translating, Rewriting and the Manipulation of Literary Fame. London: Routledge.

[7] Heylen,R. (1993). Translation, Poetics \& the Stage: Six French Hamlets. London \& New York: Routledge.

[8] Draszewski, C.S. (1998). Four Translation Strategies Determined by the Particular Needs of the Receptor. Lewiston and Queenston and Lampeter: The Edwin Mellen Press.

[9] Newmark, Peter.(1988). A Textbook of Translation. UK: Prentice Hall

[10] Nida, Eugene. (1964a). Toward a Science of Translating. With Special Reference to Principles and Procedures Involved in Bible Translating. Leiden: E. J. Brill.

[11] Toury, Gedion. (2001). Descriptive Translation Studies and Beyond. Shanghai: Shanghai Foreign Language Education Press.

[12] Liao Qiyi. (2001). Contemporary British Translation Theory. Hubei: Hubei Education Press.

[13] Wang Dongfeng, (2000). Cultural Position of Translation and Cultural attitude of the Translator, China Translation, Vol4, 1-7

[14] Han Ziman. (2000). Cultural Imbalance and Translation in Literature, Vol2, p39-43.

[15] Wang Hongzhi. (2000). Translation and Writing — on Translated Novels in Modern China, Beijing: Beijing University Prress,

[16] Luo Xinzhang. (1995). Style, Exaggeration and Others, China Translation, Vol4,p23-25 
Wenfen Yang was born in Zhucheng, China in 1965. She received her bachelor's degree in English linguistics and literature from Qufu Teacher's Universety, China in 1982.

She is currently an associate professor in the School of Foreign Languages, Qingdao University of Science and Technology, Qingdao, China. Her research interests include Translation and Contrast of Chinese and English. 